\title{
Pyocytes Measurement
}

National Cancer Institute

\section{Source}

National Cancer Institute. Pyocytes Measurement. NCI Thesaurus. Code C156524.

The determination of the amount of pyocytes present in a sample. 